\title{
Oral administration of Cervus nippon mantchuricus extract suppresses 2,4-dinitrochlorobenzene-induced atopic dermatitis in BALB/c mice and inflammatory effects in mast cells
}

\author{
SE HYANG HONG ${ }^{1}$, JIN MO KU ${ }^{1}$, HYO IN KIM ${ }^{1}$, SOL JI LEE ${ }^{1}$, YE SEUL LIM ${ }^{1}$, \\ HYE SOOK SEO ${ }^{2}$, YONG CHEOL SHIN ${ }^{2}$ and SEONG-GYU KO ${ }^{2}$ \\ ${ }^{1}$ Department of Science in Korean Medicine, Graduate School; ${ }^{2}$ Department of Preventive Medicine, \\ College of Korean Medicine, Kyung Hee University, Seoul 02447, Republic of Korea
}

Received February 9, 2018; Accepted August 30, 2018

DOI: $10.3892 /$ ijmm.2018.3856

\begin{abstract}
Cervus nippon mantchuricus extract, known as nok-gol (NGE) in Korean, is useful for the treatment of various inflammatory diseases, including bone resorption and neutropenia. However, NGE has not been widely investigated, and its efficacy and safety remain to be fully elucidated. In the present study, histological analysis, blood analysis, reverse transcription-semi-quantitative polymerase chain reaction analysis and enzyme-linked immunosorbent assays were performed to verify the inhibitory effect of NGE on atopic dermatitis (AD) in BALB/c mice and on inflammatory effects in HMC-1 human mast cells. NGE suppressed the development of $\mathrm{AD}$ in mice, and decreased the infiltration of inflammatory cells, mast cells and $\mathrm{CD}^{+} \mathrm{T}$ cells into AD skin lesions. NGE also decreased leukocyte levels induced by 2,4-dinitrochlorobenzene (DNCB). NGE alleviated AD-like inflammatory symptoms in mice by suppressing the production of $\mathrm{CD}^{+}$ $\mathrm{T}$ cells. NGE downregulated the mRNA expression of inflammatory cytokines induced by DNCB. It also decreased the serum immunoglobulin E concentration and inflammatory cytokine levels in DNCB-treated BALB/c mice. The in vitro experiments demonstrated that NGE reduced the phorbol 12-myristate 13-acetate + ionomycin-induced expression of pro-inflammatory cytokines interleukin (IL)-4, IL-13, tumor necrosis factor- $\alpha$, and IL- 6 in HMC- 1 cells. Taken together, the results of the present study indicated that NGE suppressed the progression of $\mathrm{DNCB}$-induced $\mathrm{AD}$ in $\mathrm{BALB} / \mathrm{c}$ mice and
\end{abstract}

Correspondence to: Professor Seong-Gyu Ko, Department of Preventive Medicine, College of Korean Medicine, Kyung Hee University, 26 Kyungheedae, Dongdaemun, Seoul 02447, Republic of Korea

E-mail: epiko@khu.ac.kr

Key words: atopic dermatitis, anti-inflammatory, human mast cell, leukocyte, immunoglobulin $\mathrm{E}, \mathrm{CD} 4{ }^{+} \mathrm{T}$ cell, 2,4-dinitrochlorobenzene reduced inflammatory effects in HMC-1 cells. This suggests that NGE may be a useful drug for the treatment of AD.

\section{Introduction}

Atopic dermatitis (AD) is a common chronic skin disorder that can have a significant impact on the human population worldwide. AD precedes the development of allergic disorders, including asthma, rhinitis and food allergy $(1,2)$. The pathogenesis of $\mathrm{AD}$ has been largely attributed to abnormalities in the adaptive immune system. All AD conditions are characterized by elevated peripheral eosinophilia counts and increased serum immunoglobulin E (IgE) levels $(3,4)$. Proliferating Thelper (Th) cells that develop into effector T cells differentiate into two major subtypes of cells, known as Th1 and Th2 cells. Th1 cells are the host immune effectors against intracellular bacteria and protozoa. Th1 cells are triggered by interleukin (IL)-12, and their effector cytokines are interferon- $\gamma$ and IL-2. Th2 cells are the host immune effectors against extracellular parasites, including helminths. They are triggered by IL-4 and IL-2, and their effector cytokines are IL-4, IL-5, IL-9, IL-10, IL-13 and IL-25. Peripheral eosinophilia is associated with Th2 cytokines, including IL-4 and IL-13, which are involved in AD and other allergic disorders. IL-4 and IL-13 are essential in the initial phase of tissue inflammation and in the increased expression of adhesion molecules on endothelial cells (5). These two cytokines are also responsible for the differentiation of allergen-specific Th2 cells and the class switching of activated B cells to IgE-producing cells. The balance of the earliest determined $\mathrm{CD}^{+} \mathrm{T}$ helper cell subsets, Th1 and Th2, is important in allergic and autoimmune diseases.

Eosinophils are important in the pathogenesis of allergic diseases, including asthma $(6,7)$ and $\operatorname{AD}(8,9)$. Their role in the occurrence of tissue damage during the chronic phase of the disease is particularly significant. $\operatorname{IgE}$ mediates mast cell activation, which results in the release of preformed histamine and inflammatory mediators, including chemokines and cytokines (10). In AD skin lesions, $\mathrm{CD}^{+} \mathrm{T}$ cells, eosinophils, mast and dendritic cells are markedly increased in the dermis; these 
cytokines promote Th2-type T cell responses (11) and are found in skin lesions during the acute phase of $\mathrm{AD}$ (12). However, Th1 cells are also involved. In addition, regulated immune responses are accompanied by a combination of Th2 and Th1 responses during the chronic phase of $\mathrm{AD}$ (12). AD triggers the production of pro-inflammatory cytokines, including tumor necrosis factor (TNF)- $\alpha$ and macrophage-derived cytokines (IL-6) (13). Therefore, the acute and chronic phases of AD are characterized by the marked infiltration of cells, particularly, $\mathrm{CD}^{+} \mathrm{T}$ cells, into the region of skin involved (14).

$\mathrm{BALB} / \mathrm{c}$ mice exhibit traits similar to those noted in $\mathrm{AD}$, including an increased level of IgE and chronic dryness. These mice are generally adopted as animal experimental models for AD. In addition, this is supported by the effects of 2,4-dinitrochlorobenzene (DNCB) sensitization on the production of Th1 cytokines and Th2 cytokines (15). DNCB is an organic compound with the formula $\left(\mathrm{O}_{2} \mathrm{~N}\right)_{2} \mathrm{C}_{6} \mathrm{H}_{3} \mathrm{Cl}$. It is a yellow solid that is soluble in organic solvents. DNCB induces a type IV hypersensitivity reaction in almost all individuals exposed to it, therefore, it is used medically to assess $\mathrm{T}$ cell activity in patients. This diagnostic test is useful in immunocompromised patients. DNCB can also be used to treat warts, however, DNCB can cause contact dermatitis. Previous studies have indicated that contact allergens can be discriminated from respiratory sensitizers on the basis of cytokine production in the lymph nodes of BALB/c mice $(16,17)$. Cervus nippon mantchuricus extract, which is a deer bone extract known as nok-gol (NGE) in Korean, is one of the most famous Korean traditional medicines; NGE has been widely used as a bone nutrient. In our previous study, it was found that NGE alleviated neutropenia and activated macrophages in vivo and in vitro (18). In previous studies, it has also been found that the oral administration of NGE is useful for the treatment of memory loss (19) and bone resorption (20), as an anti-aging treatment (21), for the activation of macrophages (22), enhancement of immune system activity (23), and the control of various inflammatory diseases (24-26). It has been confirmed that NGE is effective against a variety of inflammatory diseases, therefore, it is expected to be effective for inflammatory skin diseases, including AD.

The aim of the present study was to examine whether NGE suppresses the progression of AD-like skin inflammation in $\mathrm{BALB} / \mathrm{c}$ mice. Skin thickness measurements and histological evaluation, in addition to the estimation of leukocyte levels, proinflammatory cytokine mRNA levels, and serum total IgE and cytokine levels, were assessed in the study. The results showed that NGE significantly inhibited DNCB-induced AD-like skin inflammation in BALB/c mice. In addition, the anti-inflammatory effects of NGE on human mast cells were investigated. For this purpose, the cells were stimulated with phorbol 12-myristate 13-acetate (PMA)+ionomycin to produce proinflammatory cytokines. PMA is a diester of phorbol and a potent tumor promoter often used in biomedical investigations to activate the signal transduction enzyme protein kinase $\mathrm{C}$ (PKC). The effects of PMA on PKC result from its similarity to one of the natural activators of classic PKC isoforms, diacylglycerol. PMA is a small molecule drug. Ionomycin is an ionophore produced by the bacterium Streptomyces conglobatus. It is used to increase the intracellular level of calcium $\left(\mathrm{Ca}^{2+}\right)$ and as a tool for understanding
$\mathrm{Ca}^{2+}$ transport across biological membranes. It is also used to stimulate the intracellular production of the following cytokines: Interferon, perforin, IL-2 and IL-4, usually in conjunction with PMA (27). These cytokines are important in the inflammatory response (27). The results of the present study demonstrated that NGE inhibited the development of DNCB-induced AD-like symptoms, suggesting that NGE may be a useful therapeutic drug for the treatment of AD.

\section{Materials and methods}

NGE preparation. The NGE was prepared by Nongshim Corporation (Seoul, Korea), and contained $88.8 \%$ crude protein, $1.9 \%$ crude fat, $2.2 \%$ crude ash and $3.0 \%$ moisture. The total ganglioside content as sialic acid in the extract was $0.09 \%$. The total amino acid and free amino acid contents in the extract were 922.5 and $8.21 \mathrm{mg} / \mathrm{g}$, respectively. NGE, as a water-extracted white powder, was dissolved in water for the in vivo and in vitro experiments. Further information on the NGE production process can be requested from the company (http://nongshim.co.kr).

Cell culture. The HMC-1 human mast cells were purchased from the Korea Cell Line Bank (Seoul, Korea). The cell line was grown in Iscove's modified Dulbecco's medium (Welgene, Daegu, Korea) supplemented with heat-inactivated $10 \%$ fetal bovine serum (FBS; Welgene) and $1 \%$ Penicillin-Streptomycin solution (1X; Welgene) in a $5 \% \mathrm{CO}_{2}$ incubator at $37^{\circ} \mathrm{C}$.

Cell viability assay. The HMC- 1 cells $\left(1 \times 10^{4}\right.$ cells/well $)$ were plated in 96-well culture plates and incubated for $24 \mathrm{~h}$. Subsequently, the HMC-1 cells were treated with $5 \mathrm{ng} / \mathrm{ml} \mathrm{PMA}$ and $500 \mathrm{ng} / \mathrm{ml}$ ionomycin (Sigma, EMD Millipore, Billerica, MA, USA) in the presence or absence of various concentrations of NGE $(5,25,100,250,500$, and $1,000 \mathrm{mg} / \mathrm{ml})$. Following $24 \mathrm{~h}$ of incubation, $10 \mu \mathrm{l}$ of WST solution was added to each well of the plate, and the plate was incubated in the dark at $37^{\circ} \mathrm{C}$ for an additional $1 \mathrm{~h}$. The optical density was measured at $450 \mathrm{~nm}$ using an enzyme-linked immunosorbent assay (ELISA) plate reader (Versa Max; Molecular Devices LLC, Sunnyvale, CA, USA).

Animals. Male, 6-week-old BALB/c mice $(20 \pm 2 \mathrm{~g})$ were purchased from Orient Bio, Inc. (Sungnam, Korea). The mice were randomized into three groups: Vehicle (saline), DNCB, and $\mathrm{DNCB}+\mathrm{NGE}$, each comprising six mice. All mice were maintained in a pathogen-free environment and allowed free access to food and water; they were maintained on a $12-\mathrm{h}$ light/dark cycle at a temperature of $24^{\circ} \mathrm{C}$. All procedures performed on the mice were approved by the Animal Care Center of Kyung Hee University [approval no. KHUASP (SE)-16-095]. All methods were performed in accordance with the relevant guidelines and regulations. At the end of the experiment, the mice were sacrificed by $\mathrm{CO}_{2}$ inhalation, and cardiac blood was collected.

Sensitization and treatment. The procedure for the induction of AD-like skin lesions is shown in Fig. 2A. For this purpose, the dorsal skin of the mouse was shaved and coated with $100 \mu 1$ of $2 \%$ DNCB in $1 \times 1 \mathrm{~cm}$ patches. At 1 week post-sensitization, 
the dorsal skin was challenged with $100 \mu 1$ of $0.2 \%$ DNCB solution twice per week (first and fourth day of each week). The NGE was administered orally to the mice for 2 weeks following sensitization with DNCB. Following the final application of NGE, the mice were sacrificed, and immunological and histological assessments were performed. The method was performed as described previously (28).

Determination of skin thickness and spleen weight. The thickness of the dorsal skin was measured with digital calipers (Mitutoyo, Kawasaki, Japan) prior to sacrifice. For each mouse, three different sites on the dorsal skin were measured randomly, and the measurements were averaged. The entire spleen was removed from the mice following sacrifice and was weighed.

Histological observation. A section of the skin biopsies was fixed in $4 \%$ paraformaldehyde and embedded in frozen section compound (Surgipath FSC22 Clear Leica Biosystems GmbH, Wetzlar, Germany) on dry ice. Skin sections measuring $20 \mu \mathrm{m}$ in thickness were cut and stained with hematoxylin and eosin (H\&E) to visualize inflammatory cells (neutrophils and mononuclear cells) or with toluidine blue to visualize mast cells, and were examined under light microscopy (Olympus Corporation, Tokyo, Japan). The numbers of mast cells and inflammatory cells were counted in 10 regions of high-power fields at x400 magnification.

Immunohistochemistry. The expression of $\mathrm{CD}^{+}$lymphocytes was detected by immunohistochemical analysis using a mouse monoclonal anti-CD4 ${ }^{+}$antibody (cat. no. SC-7219; Santa Cruz Biotechnology, Inc., Dallas, TX, USA). The skin sections were hydrated. Following microwave treatment, the sections were treated with $3 \%$ hydrogen peroxide in PBS for $15 \mathrm{~min}$ to inhibit the endogenous peroxidase activity of the blood cells. The sections were blocked with $5 \%$ bovine serum albumin (Sigma, EMD Millipore) in PBS for $1 \mathrm{~h}$ at room temperature. The skin sections were incubated with the mouse monoclonal $\mathrm{CD} 4^{+}$antibody (1:100 dilution) overnight at $4^{\circ} \mathrm{C}$ and subsequently incubated with a biotinylated anti-mouse IgG secondary antibody (1:50 dilution; Vectastain ABC kit; cat. no. PK-6102; Vector Laboratories, Inc., Burlingame, CA, USA) for $1 \mathrm{~h}$ at room temperature. The sections were treated with avidin-biotin horseradish peroxidase (HRP) complex (Vectastain ABC kit; cat. no. PK-4000; Vector Laboratories, Inc., Burlingame, CA, USA) for $30 \mathrm{~min}$ at $4^{\circ} \mathrm{C}$ and finally stained with diaminobenzidine tetrachloride (DAB) as a substrate. The slides were mounted with an aqueous mounting solution (Permount; Thermo Fisher Scientific, Inc., Waltham, MA, USA) and cover-slipped. All the sections were analyzed using a ZEISS Scope A1 light microscope (Carl Zeiss AG, Oberkochen, Germany), and images were captured using a digital video camera.

Blood analysis. Whole blood samples were collected by cardiac puncture. The blood was placed in Vacutainer ${ }^{\mathrm{TM}}$ tubes containing EDTA (BD Biosciences, San Jose, CA, USA) by centrifugation $\left(200 \mathrm{x} \mathrm{g}, 20 \mathrm{~min}, 4^{\circ} \mathrm{C}\right)$. Anticoagulated blood was processed to determine the hematological parameters of white blood cells (WBCs), lymphocytes, monocytes, eosinophils, basophils and neutrophils in a HEMAVET 950 hematology system (Drew Scientific, Inc., Dallas, TX, USA) in accordance with the manufacturer's recommendations.

ELISA. The total IgE levels in the serum of the mice were determined by sandwich ELISA using the BD Pharmingen mouse IgE and human ELISA sets (BD Biosciences, San Diego, CA, USA). Briefly, the plates were coated with capture antibody in ELISA coating buffer (Sigma, EMD Millipore) and incubated overnight at $4^{\circ} \mathrm{C}$. The plates were then washed with PBS-Tween-20 (0.05\%) and subsequently blocked (10\% FBS in PBS) for $1 \mathrm{~h}$ at $20^{\circ} \mathrm{C}$. Serial dilutions of standard antigen or sample in dilution buffer (10\% FBS in PBS) were added to the plates, and the plates were incubated for $2 \mathrm{~h}$ at $20^{\circ} \mathrm{C}$. Following washing, biotin-conjugated anti-mouse IgE (1:500 dilution) and streptavidin-HRP conjugate (1:250 dilution) were added to the plates, and the plates were incubated for $1 \mathrm{~h}$ at $20^{\circ} \mathrm{C}$. Finally, tetramethylbenzidine substrate solution was added to the plates for 15 min incubation in the dark, and a $2 \mathrm{~N} \mathrm{H}_{2} \mathrm{SO}_{4}$ solution was added to terminate the reaction. The optical densities were measured at $450 \mathrm{~nm}$ on an automated ELISA reader (VersaMax; Molecular Devices LLC). The levels of IL-10 and IL-12 in the plasma and the levels of IL-4, IL-13, TNF- $\alpha$ and IL-6 in the cell line were also measured by sandwich ELISA using the BD Pharmingen mouse and human ELISA sets. The subsequent procedure followed the same protocol described above.

Reverse transcription-semi-quantitative polymerase chain reaction analysis. The cells were harvested by centrifugation $\left(500 \mathrm{x} \mathrm{g}, 20 \mathrm{~min}, 4^{\circ} \mathrm{C}\right.$ ) and the pellet was washed with ice-cold PBS. RNA was isolated from the cells using the Easy-Blue RNA extraction kit (iNtRON Biotech, Sungnam, Korea) according to the manufacturer's protocol. The isolated RNA content was measured using a NanoDrop ND-1000 spectrophotometer (NanoDrop Technologies, Inc., Wilmington, DE, USA). Total cellular RNA ( $2 \mu \mathrm{g})$ from each sample was reverse transcribed using a cDNA synthesis kit (Takara Bio, Inc., Otsu, Japan). The sqPCR analysis was performed with a $20-\mu 1$ reaction mixture consisting of DNA template, each gene-specific primer at a concentration of $10 \mathrm{pM}, 10 \mathrm{X}$ Taq buffer, $2.5 \mathrm{mM}$ dNTP mixture, and 1 unit of Taq DNA polymerase (Takara Bio, Inc.). PCR was performed according to the instructions of the Takara Taq kit as follows: Pre-DNA denaturation at $95^{\circ} \mathrm{C}$ for $3 \mathrm{~min}$; and 30 cycles of DNA denaturation at $95^{\circ} \mathrm{C}$ for $45 \mathrm{sec}$; annealing for $40 \mathrm{sec}$ at $56^{\circ} \mathrm{C}$; elongation at $72^{\circ} \mathrm{C}$ for $50 \mathrm{sec}$. The PCR reaction was performed using a SimpliAmp Thermal Cycler (Applied Biosystems; Thermo Fisher Scientific, Inc.). The PCR products were subsequently separated using agarose gel electrophoresis $[5 \%(\mathrm{w} / \mathrm{v})]$ and were stained with ethidium bromide at room temperature for $5 \mathrm{~min}$. All experiments were performed in triplicate. The relative optical density ratio was calculated using ImageJ software (version 1.42q; National Institutes of Health, Bethesda, MD, USA) with GAPDH as an internal control. The primer sequences used for human and/or mouse IL-4, IL-6, TNF- $\alpha$ and GAPDH are shown in Table I.

Statistical analysis. All experimental results were expressed as the mean \pm standard deviation or the mean \pm standard error of the mean of at least three separate tests. $\mathrm{P}<0.05$ was 
Table I. Sequences of primers for polymerase chain reaction analysis.

\begin{tabular}{lcc}
\hline Primer type & Primer name & \multicolumn{1}{c}{ Primer sequence } \\
\hline Mouse & IL-6 & F: 5'-CAAGAGACTTCCATCCAGTTGC-3' \\
& IL-4 & R: 5'-TTGCCGAGTTCTCAAAGTGAC-3' \\
& F: 5'-TCGGCATTTTGAACGAGGTC-3' \\
& RNF- $\alpha$ & F: 5'-AAAAAGCCCGAAAGAGTCTC-3' \\
& & R: 5'-TACAGCACAGAAAGCATGATC-3' \\
& GAPDH & F: 5'-GAGGGGCCATCCACAGTCTTC-3' \\
& R: 5'-CATCACCATCTTCCAGGAGCG-3' \\
& IL-6 & F: 5'-AACCTTCCAAAGATGGCTGAA-3' \\
& R: 5'-CAGGAACTGGATCAGGACTTT-3' \\
& IL-4 & F: 5'-TGCCTCCAAGAACACAACTG-3' \\
& R: 5'-CTCTGGTTGGCTTCCTTCAC-3' \\
& TNF- $\alpha$ & F: 5'-TGAGCACTGAAAGCATGATCC-3' \\
& R: 5'-ATCACTCCAAAGTGCAGGAG-3' \\
& GAPDH & F: 5'-CGTCTTCACCACCATGGAGA-3' \\
& R: 5'-CGGCCATCACGCCACAGTTT-3'
\end{tabular}

IL, interleukin; TNF- $\alpha$, tumor necrosis factor- $\alpha$; F, forward; R, reverse.

considered to indicate a statistically significant difference and $\mathrm{P}<0.05,<0.01$, and $<0.001$ have been assigned respective symbols in figures. Statistical significance was determined using a one-way analysis of variance followed by Tukey-Kramer multiple comparisons post-tests to analyse differences between groups. Statistical analyses were performed using PRISM software (version 5.0; GraphPad Software Inc., La Jolla, CA, USA.).

\section{Results}

NGE inhibits the agonist-induced production of cytokines in HMC-1 cells. Mast cell mediators, including tryptase and histamine, contribute to the induction of pruritus in AD (29). In the present study, the viability of HMC-1 cells was examined following treatment with various concentrations of NGE (Fig. 1A). NGE did not induce any cytotoxicity in HMC-1 cells over a $24-\mathrm{h}$ period. The PMA + ionomycin-mediated stimulation of HMC-1 cells has been shown to significantly increase the production of cytokines and chemokines (27). The present study examined the role of NGE in the suppression of cytokine expression in HMC-1 cells. NGE cotreatment significantly reduced the agonist-stimulated production of IL-4, IL-13, TNF- $\alpha$ and IL-6 in the HMC-1 cells (Fig. 1B). Further experiments were performed to determine whether NGE regulates the expression of cytokines at the transcriptional level. RT-qPCR analysis showed that the mRNA levels of IL-4, IL- 6 and TNF- $\alpha$ were induced by agonist treatment and were decreased by NGE cotreatment in HMC-1 cells (Fig. 1C). In particular, treatment with NGE in a concentration of $250 \mu \mathrm{g} / \mathrm{ml}$ reduced the levels of IL- 4 and IL- 6 to the control levels. These results suggested that NGE regulates proinflammatory cytokine production in HMC-1 cells.
$N G E$ suppresses the development of $A D$ in $B A L B / c$ mice. Following the application of DNCB to the skin of mice to induce an acute allergic reaction, NGE was administered orally for 2 weeks at a regular time every day. The level of toxicity and the body weight was measured twice a week to determine the degree of stress caused by the NGE treatment (Fig. 2A). Body weight and food intake were also monitored throughout the study. As a result, it was found that the mice in the vehicle group $(n=6)$ were higher in weight compared with those in the DNCB-treated $(n=6)$ or NGE-treated $(n=6)$ groups. It was also found that the mice in the DNCB-treated group did not exhibit any changes in food intake but exhibited a marginal decrease $(15 \%)$ in body weight compared with those in the vehicle-treated group (Fig. 2C). To investigate the effects of NGE on DNCB-induced AD-like symptoms in BALB/c mice, skin lesions were examined and the skin thickness and spleen weight were measured. It was found that DNCB induced AD in BALB/c mice (Fig. 2B). In addition, the skin thickness was gradually increased in the DNCB-treated BALB/c mice compared with that in the non-DNCB-treated mice, whereas NGE markedly attenuated the DNCB-induced increase in skin thickness (Fig. 2D). Similarly, the spleen weight of the DNCB-treated BALB/c mice was heavier than that of the mice in the vehicle group, whereas NGE significantly decreased the DNCB-induced increase in spleen weight (Fig. 2E). These finding suggested that NGE alleviated DNCB-induced AD.

$N G E$ decreases the infiltration of inflammatory cells, mast cells and $C D 4^{+} T$ cells into AD skin lesions. To determine whether NGE decreases the infiltration of inflammatory cells (neutrophils and mononuclear cells) into AD skin lesions, H\&E staining of skin sections was performed following topical administration of NGE. The infiltration 

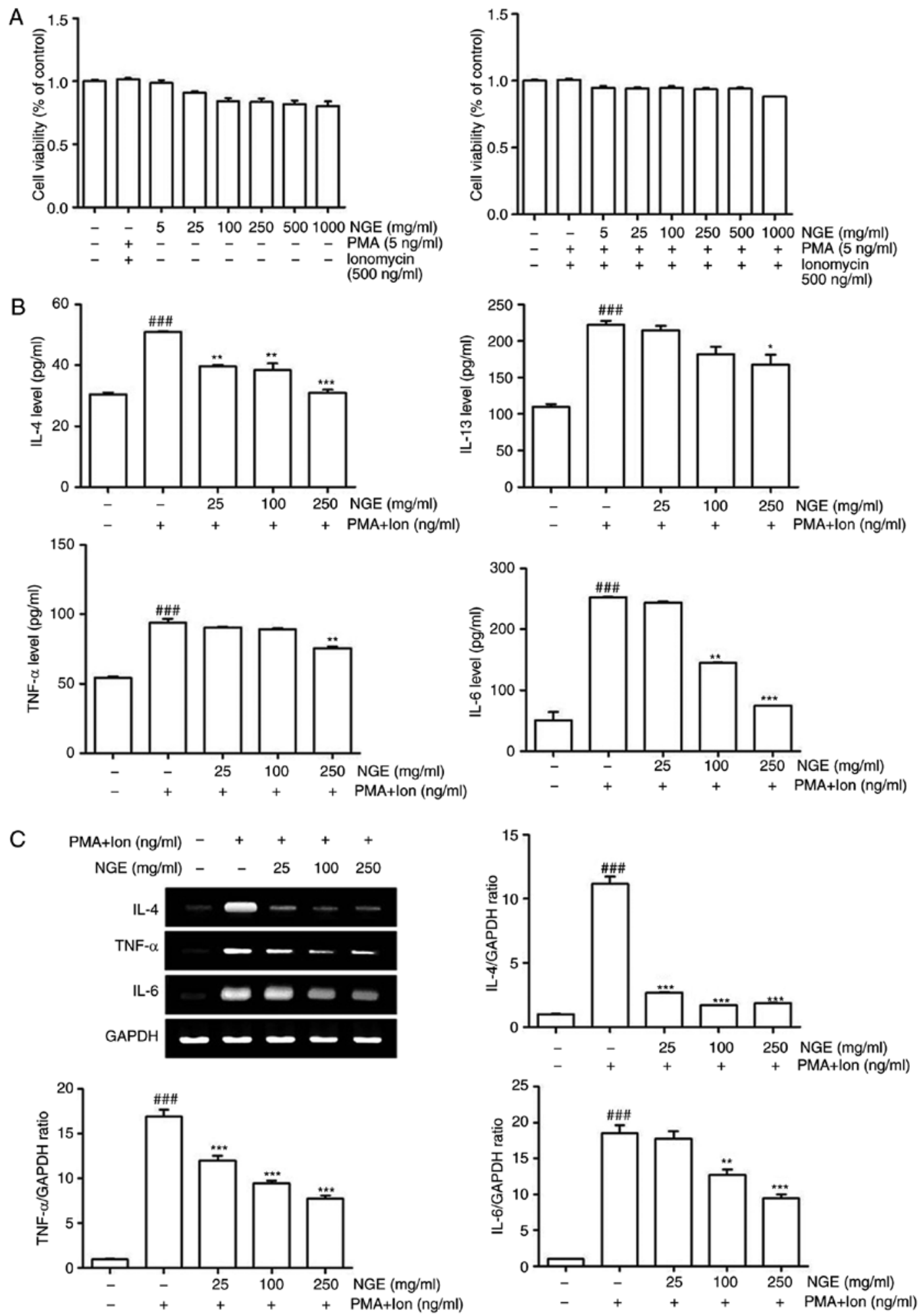

Figure 1. Effect of NGE on HMC-1 cells with PMA + ionomycin. (A) HMC-1 cells were treated with various concentrations of NGE for 24 h following pretreatment with vehicle (left panel) or with PMA + ionomycin (right panel) for $1 \mathrm{~h}$. Following treatment, cell viability was measured using a WST assay. (B) Levels of IL-4, IL-13, TNF- $\alpha$ and IL-6 in cell culture supernatants were measured via enzyme-linked immunosorbent assay. HMC-1 cells were stimulated with 5 ng/ml PMA $+500 \mathrm{ng} / \mathrm{ml}$ ionomycin for $1 \mathrm{~h}$ and treated with varying concentrations of NGE for $24 \mathrm{~h}$. (C) mRNA levels of IL-4, TNF- $\alpha$ and IL-6 were measured by RT-sqPCR analysis in the treated HMC-1 cells. The bar graphs show quantitation of the RT-sqPCR data; data are presented as the mean \pm standard error of the mean. ${ }^{\# \# \#} \mathrm{P}<0.001$, compared with the untreated group; ${ }^{* *} \mathrm{P}<0.01$ and ${ }^{* * * *} \mathrm{P}<0.001$, compared with the PMA + ionomycin-stimulated group. NGE, nok-gol; PMA, phorbol 12-myristate 13-acetate; Ion, ionomycin; RT-sqPCR, reverse transcription-semi-quantitative polymerase chain reaction; IL, interleukin; TNF- $\alpha$, tumor necrosis factor- $\alpha$.

of inflammatory cells into the epidermis and dermis of mice in the DNCB group was observed, whereas topical
NGE decreased the infiltration of inflammatory cells into the skin (Fig. 3A). Subsequently, toluidine blue staining 
A

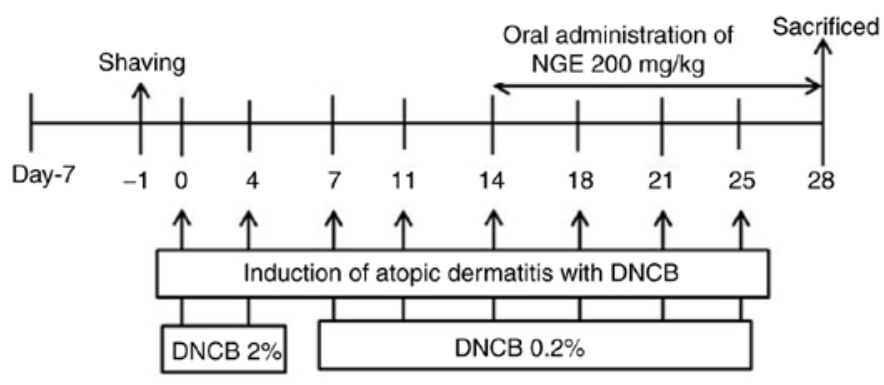

C

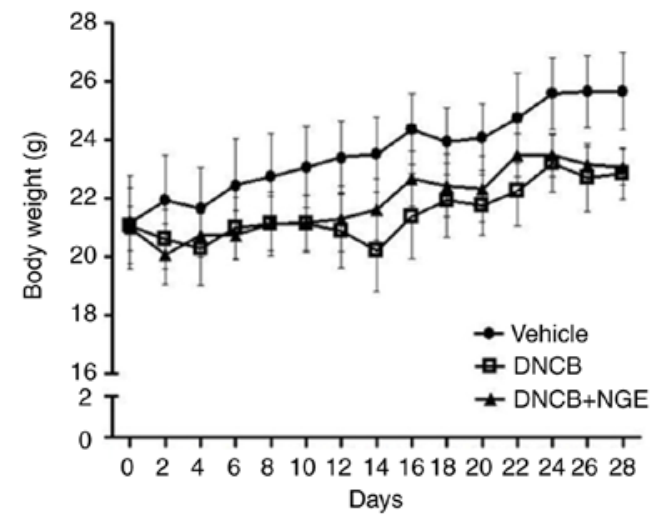

D

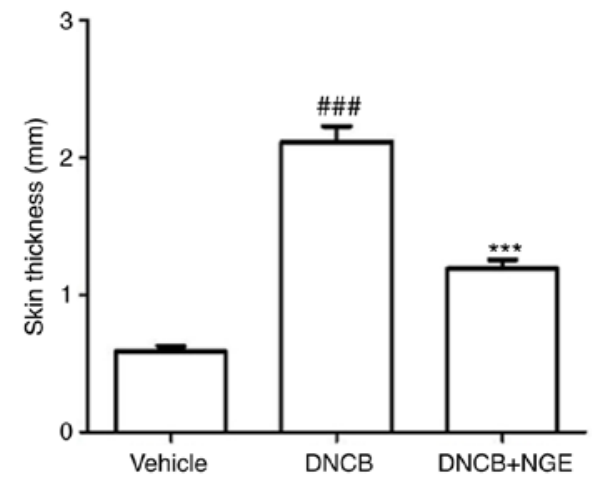

B

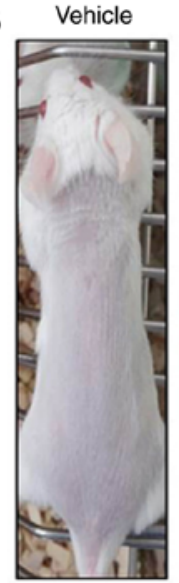

DNCB

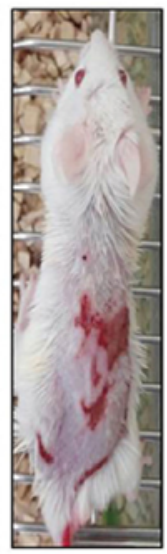

$\mathrm{DNCB}+\mathrm{NGE}$

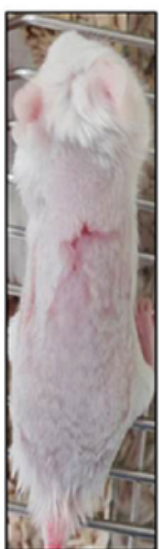

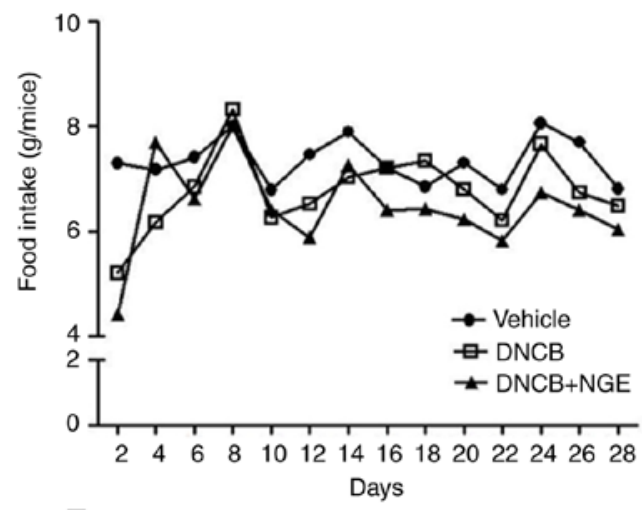

E

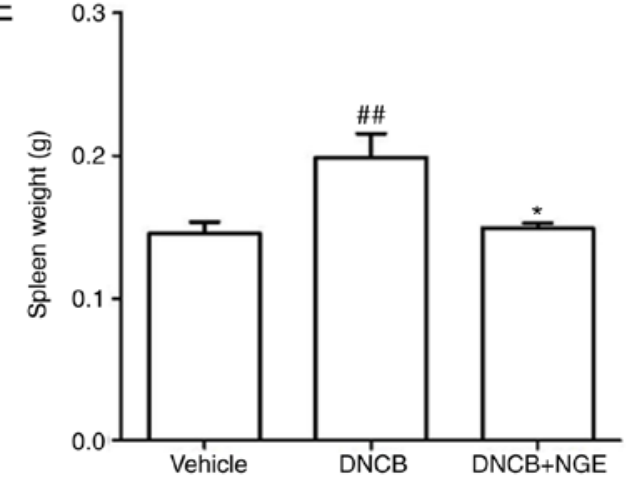

Figure 2. Effect of NGE on DNCB-induced atopic dermatitis. (A) BALB/c mice were sensitized with sequential applications of DNCB, and NGE was then orally administered every day for 2 weeks. (B) Comparison of skin manifestations in BALB/c mice in the normal and experimental groups. The BALB/c mice were sensitized with $100 \mu \mathrm{l}$ of DNCB in acetone applied to the skin. (C) Changes in body weight and food intake during treatment with NGE. The values are expressed as the mean \pm standard error of the mean $(n=6)$. (D) Dorsal skin thickness and (E) spleen weight of BALB/c mice orally administered NGE following DNCB application. ${ }^{\# \#} \mathrm{P}<0.01$ and ${ }^{\# \# \#} \mathrm{P}<0.001$, compared with the vehicle group. ${ }^{*} \mathrm{P}<0.05$ and ${ }^{* * *} \mathrm{P}<0.001$, compared with the DNCB-stimulated group. NGE, nok-gol; DNCB, 2,4-dinitrochlorobenzene.

was performed for mast cell visualization. The repeated cutaneous application of DNCB increased the dermal mast cell number. However, this effect was significantly suppressed by NGE (Fig. 3B). Immunocytochemistry was performed to measure the intracellular level of $\mathrm{CD}^{+}{ }^{+} \mathrm{T}$ cells. It was found that DNCB increased the number of $\mathrm{CD} 4^{+} \mathrm{T}$ cells, whereas NGE decreased the number of $\mathrm{CD}^{+} \mathrm{T}$ cells in the epidermis and dermis (Fig. 3C). These results indicated that NGE treatment significantly decreased the number of inflammatory cells, mast cells and $\mathrm{CD}^{+} \mathrm{T}$ cells, compared with DNCB treatment (Fig. 3D-F).

$N G E$ decreases the levels of leukocytes induced by DNCB. To investigate whether cutaneous NGE administration can decrease the levels of inflammatory cells, leukocyte levels in cardiovascular blood samples were measured using a HEMAVET 950 hematology system. It is known that WBCs, neutrophils, lymphocytes, monocytes, eosinophils and basophils are activated in the blood of patients with $\mathrm{AD}(17,30)$. In particular, eosinophils have been shown to be present in the majority of patients with $\mathrm{AD}$, and they are correlated with disease activity (31). NGE significantly decreased the numbers of WBCs, basophils, monocytes, neutrophils, eosinophils and lymphocytes induced by DNCB (Fig. 4).

$N G E$ administration downregulates the $M R N A$ expression of inflammatory cytokines induced by DNCB. In the histological analysis, the repeated cutaneous application of DNCB 
A

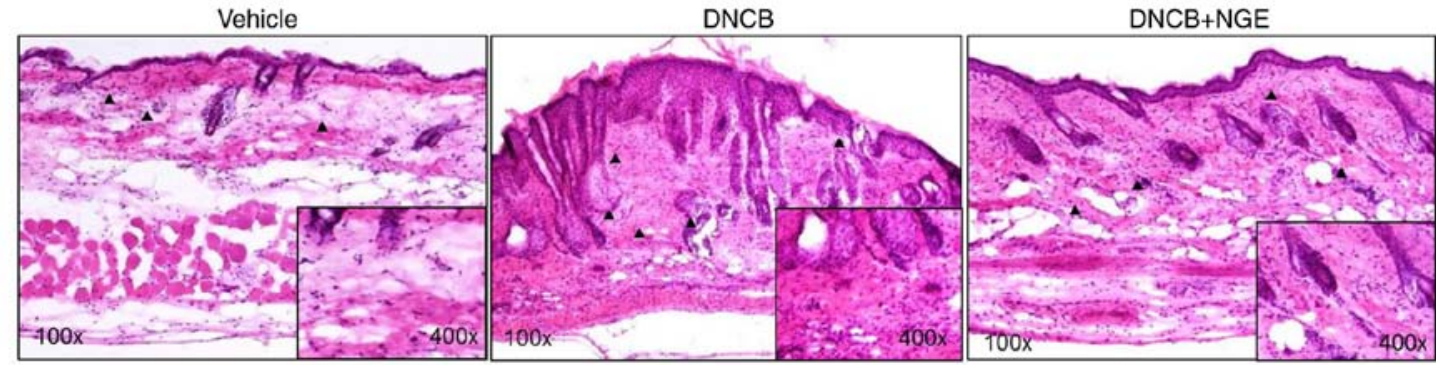

B
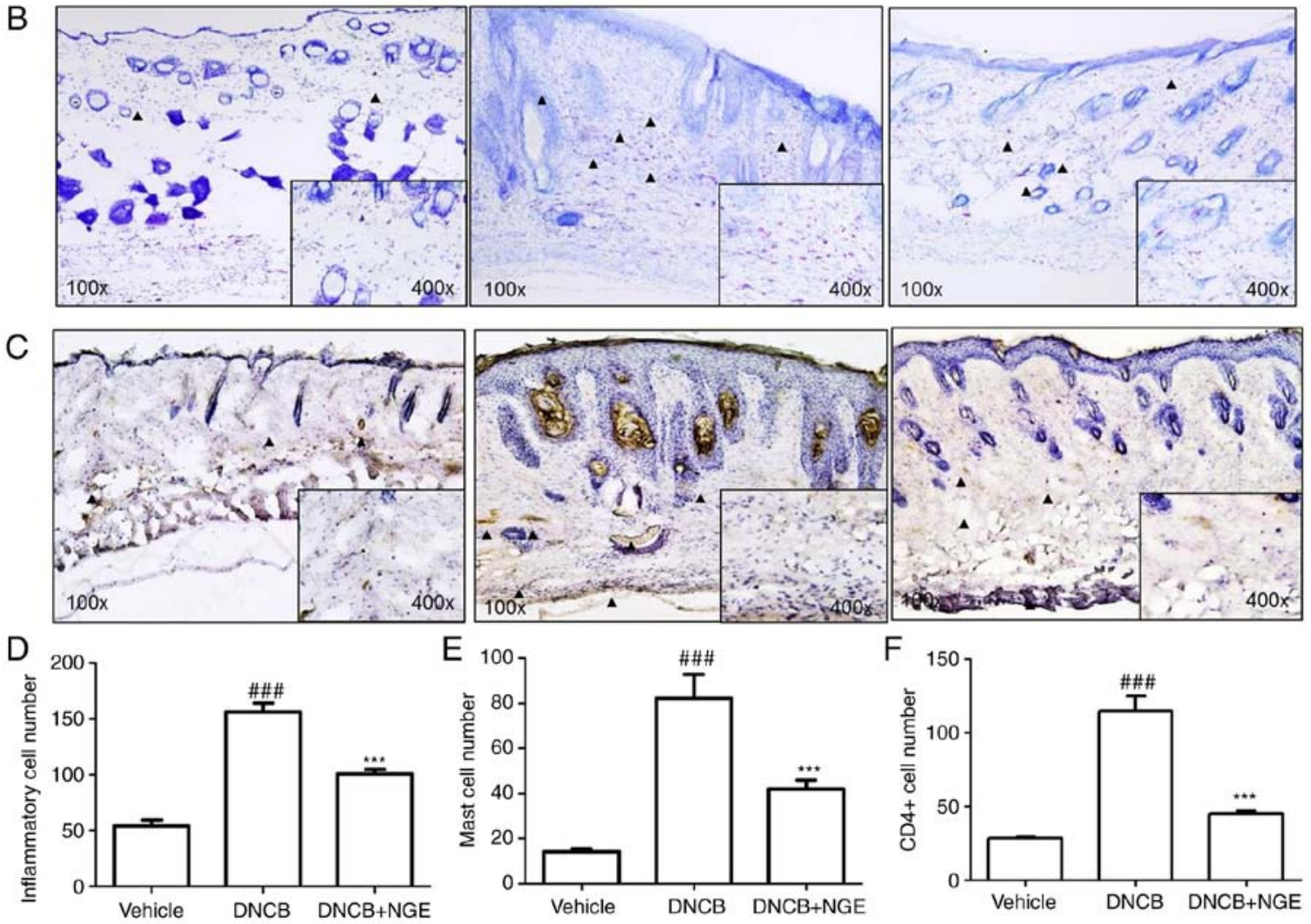

Figure 3. Effect of NGE on inflammatory cell, mast cell and CD4+ $\mathrm{T}$ cell infiltration into the dorsal skin of DNCB-induced BALB/c mice. (A) Dorsal skin sections were stained with hematoxylin and eosin. Inflammatory cells (neutrophils and mononuclear cells) are indicated by the purple spots (arrows). (B) Dorsal skin sections were stained with toluidine blue. Mast cells are indicated by the purple spots (arrows). (C) Dorsal skin sections were stained with diaminobenzidine tetrachloride. $\mathrm{CD}^{+} \mathrm{T}$ cells are indicated by the brown spots (arrows). The numbers of stained (D) inflammatory cells, (E) mast cells, and $(\mathrm{F}) \mathrm{CD}^{+} \mathrm{T}$ cells were counted and are shown graphically. The sections were evaluated using a microscope (original magnification, $\mathrm{x} 400$ ). The data are presented as the mean \pm standard error of the mean. ${ }^{\# \# *} \mathrm{P}<0.001$, compared with the vehicle group; ${ }^{* * * *} \mathrm{P}<0.001$, compared with the DNCB-stimulated group. NGE, nok-gol; DNCB, 2,4-dinitrochlorobenzene.

increased dermal mast cell numbers and $\mathrm{CD} 4^{+} \mathrm{T}$ cell numbers, and this effect was suppressed by oral administration of NGE. Activated mast cells and $\mathrm{CD}^{+}{ }^{+} \mathrm{T}$ cells secrete various chemokines and cytokines, including IL-4, IL-6 and TNF- $\alpha$. To examine whether NGE decreases the inflammatory response, RT-qPCR analysis was performed to measure the mRNA expression of IL-4, IL-6 and TNF- $\alpha$ in the AD-like skin lesions (Fig. 5). The oral administration of NGE significantly suppressed the mRNA expression of IL-4, IL-6 and TNF- $\alpha$ in the AD-like skin lesions. These results indicated that NGE downregulated the DNCB-induced mRNA expression of inflammatory cytokines.

NGE decreases the serum IgE concentration and inflammatory cytokine levels (IL-10 and IL-12) in DNCB-treated $B A L B / c$ mice. To obtain a better understanding of the mecha- nisms underlying the anti-inflammatory activity of NGE, the IgE and levels of inflammatory cytokines in serum were measured by ELISA. The hyperproduction of $\operatorname{IgE}$ is a major characteristic of $\mathrm{AD}$, and patients with $\mathrm{AD}$ often exhibit elevated levels of total and allergen-specific $\operatorname{IgE}$ antibodies in their serum. As shown in Fig. 6, the total level of IgE was markedly elevated in the DNCB-treated group compared with that in the vehicle group. However, the increase in the serum level of IgE induced by DNCB was significantly decreased by NGE treatment. In addition, the repeated topical application of DNCB significantly increased the levels of IL-10 and IL-12 in mouse serum, whereas NGE significantly inhibited this increase. These results demonstrated that NGE suppressed the DNCB-induced elevation of IgE and inflammatory cytokine levels, thereby leading to the inhibition of skin inflammation. 

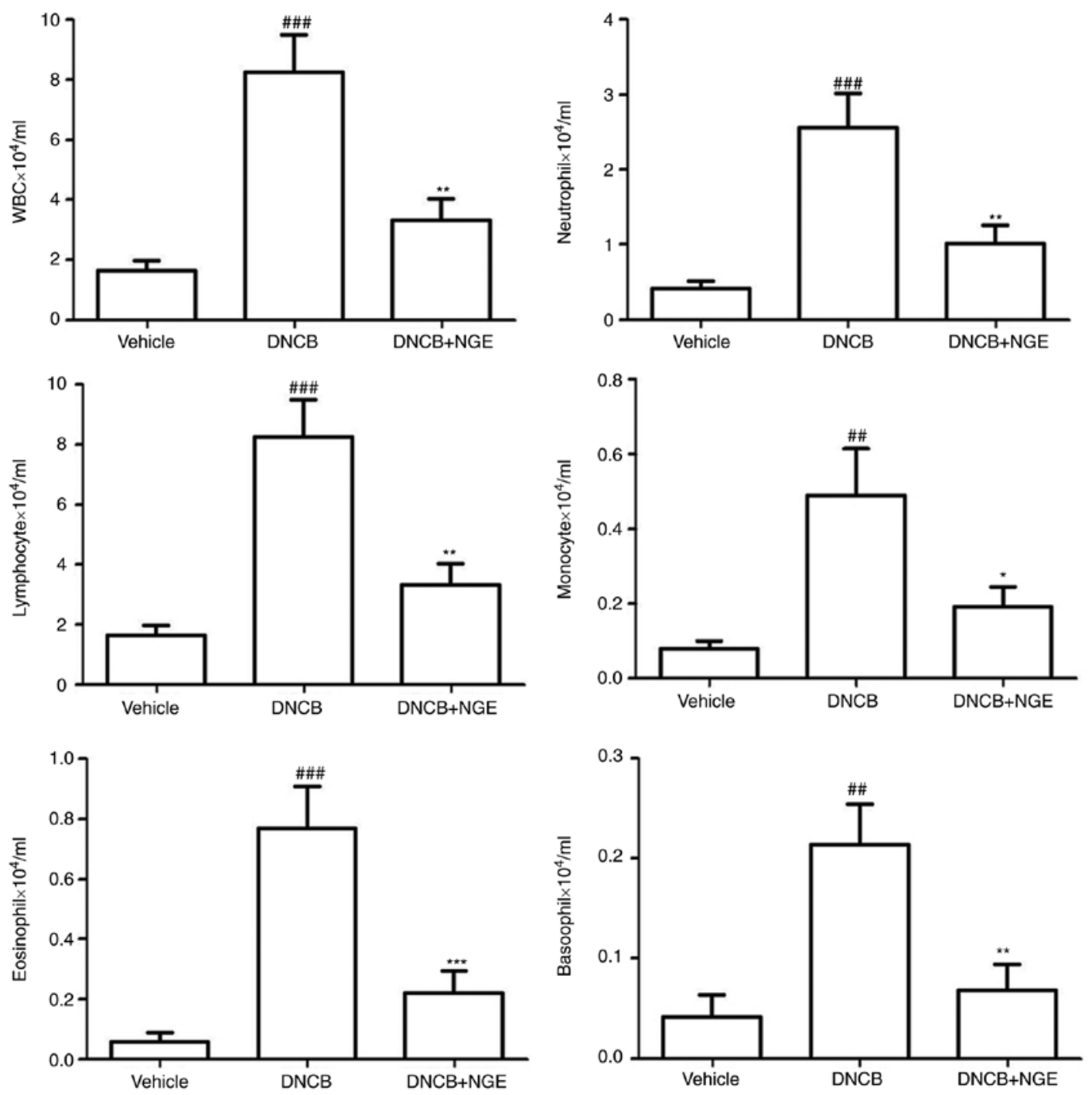

Figure 4. Effects of NGE on blood components. Blood was analyzed using the HEMAVET blood analysis system. The data are presented as the mean \pm standard error of the mean. ${ }^{\# \#} \mathrm{P}<0.01$ and ${ }^{\# \# \#} \mathrm{P}<0.001$, compared with the vehicle group; ${ }^{*} \mathrm{P}<0.05,{ }^{* *} \mathrm{P}<0.01$ and ${ }^{* * * *} \mathrm{P}<0.001$, compared with the DNCB-stimulated group. NGE, nok-gol; DNCB, 2,4-dinitrochlorobenzene; WBC, white blood cell.

\section{Discussion}

In the present study, the effect of NGE on DNCB-induced AD in $\mathrm{BALB} / \mathrm{c}$ mice was investigated. $\mathrm{AD}$ was induced by the repeated alternative application of DNCB. DNCB is the most important allergen associated with $\mathrm{AD}$, and $\mathrm{BALB} / \mathrm{c}$ mice offer a useful model, exhibiting AD-like skin lesions and an elevated level of blood IgE in response to DNCB (15-17). AD is regarded as a Th2-associated inflammatory disease of the skin characterized by eosinophil recruitment, inflammatory mediator release, and $\mathrm{IgE}$ production. IgE molecules bind to their surface receptors on mast cells, causing the release of mediators that recruit inflammatory cells and stimulate the secretion of cytokines, including IL-4 and IL-13, which are considered to drive disease pathology in patients with $\mathrm{AD}$ (32). The oral administration of NGE suppressed the development of $\mathrm{AD}$ in $\mathrm{BALB} / \mathrm{c}$ mice, alleviating the $\mathrm{AD}$-like symptoms. NGE markedly attenuated the DNCB-induced increase in skin thickness and spleen weight. Histopathological analysis revealed that NGE decreased the infiltration of inflammatory cells, mast cells and $\mathrm{CD} 4^{+}$cells into $\mathrm{AD}$ skin lesions.
Mast cells are critical for the induction of allergic diseases, including AD (29,33). Mast cells are localized in several tissues, and the activation of mast cells induces the release of histamine, tryptase and proinflammatory cytokines in tissues, resulting in allergic responses $(34,35)$. Mast cells are activated by the binding of allergen-bound IgE to the FceRI receptor (36). In the present study, NGE inhibited IgE-mediated mast cell activation, resulting in suppression of the expression of proinflammatory cytokines in mice with DNCB-induced AD and mast cell activation. Notably, although PMA treatment was an effective inducer of chemokine transcripts in HMC-1 cells, treatment with PMA + ionomycin has been shown to be ineffective for inducing chemokine expression in T cells $(37,38)$. The present study found that NGE markedly downregulated the mRNA expression of IL-4, IL-6 and TNF- $\alpha$ in HMC-1 cells exposed to PMA+ ionomycin, indicating that NGE alleviates several $\mathrm{AD}$ symptoms by controlling the transcriptional expression of Th2 cytokines. In addition, analysis via ELISA in HMC-1 cells revealed that NGE inhibited the production of IL-4, IL-13, TNF- $\alpha$ and IL-16 induced by PMA+ionomycin. These results suggested that NGE has an anti-allergy effect. 

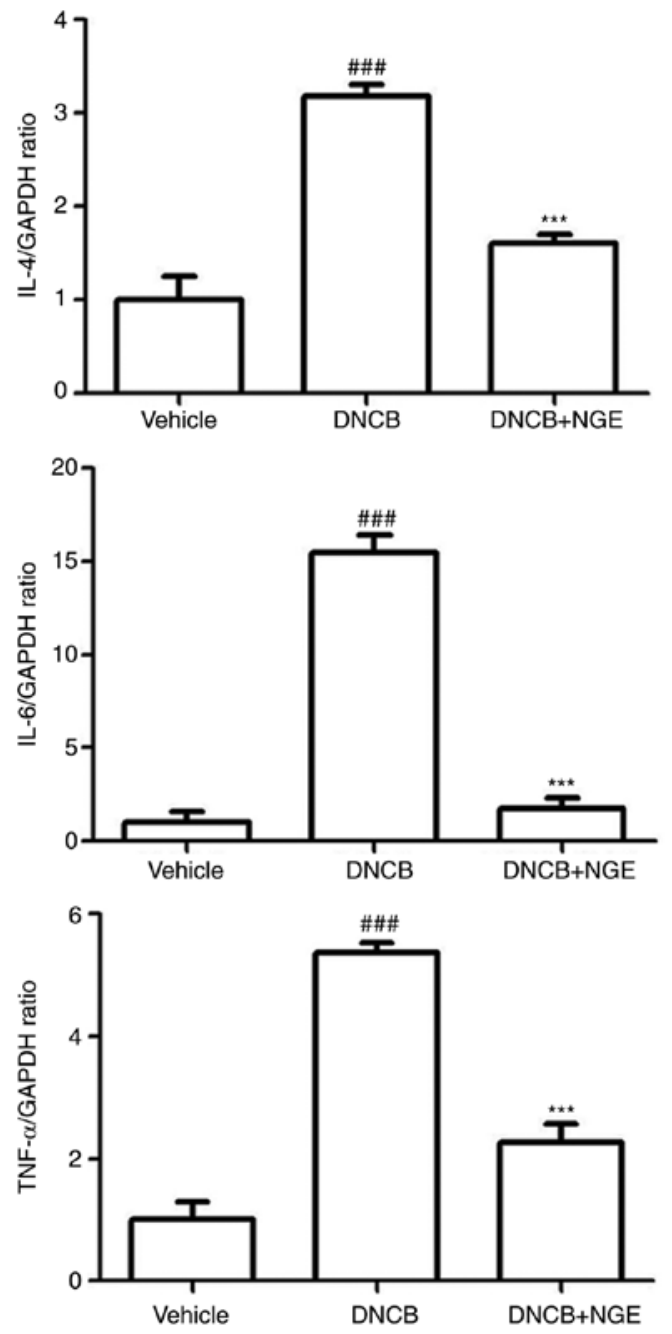

Figure 5. Effect of NGE on DNCB-induced mRNA expression of proinflammatory cytokines in BALB/c mice. The mRNA levels of IL-4, IL-6, IL-13 and TNF- $\alpha$ in AD-like skin lesions were measured by reverse transcription-polymerase chain reaction analysis. The data are presented as the mean \pm standard error of the mean. ${ }^{\# \#} \mathrm{P}<0.001$, compared with the vehicle group; ${ }^{* * *} \mathrm{P}<0.001$, compared with the DNCB-stimulated group. NGE, nok-gol; DNCB, 2,4-dinitrochlorobenzene; IL, interleukin; TNF- $\alpha$, tumor necrosis factor- $\alpha$.

Of note, $\mathrm{CD}^{+} \mathrm{T}$ cell subsets are involved in the pathogenesis of several diseases (39). $\mathrm{CD} 4^{+} \mathrm{T}$ cells generate cytokines that can stimulate other $\mathrm{T}$ cell effectors and enhance antibody production by $\mathrm{B}$ cells $(40)$. $\mathrm{CD} 4^{+} \mathrm{T}$ cells are also key factors in allergic inflammatory diseases. Th2 cells produce IL-4, which induces B cell activation and antibody class switching to IgE; the increased production of IL-4 or induction of the IL-4 signaling pathway causes allergic diseases (41).

NGE was shown to decrease the levels of leukocytes induced by DNCB. Eosinophils are involved in the pathology of allergic diseases, particularly AD $(9,42)$. The elevated eosinophil count is associated with inflammation and a change in eosinophil cell number may be a result of disease. In addition, NGE downregulated the mRNA expression of inflammatory cytokines induced by DNCB. NGE also decreased the serum $\mathrm{IgE}$ concentration and inflammatory cytokine levels in the DNCB-treated BALB/c mice.

The most common side effect associated with ointment treatment is a sensation of mild to moderate skin burning
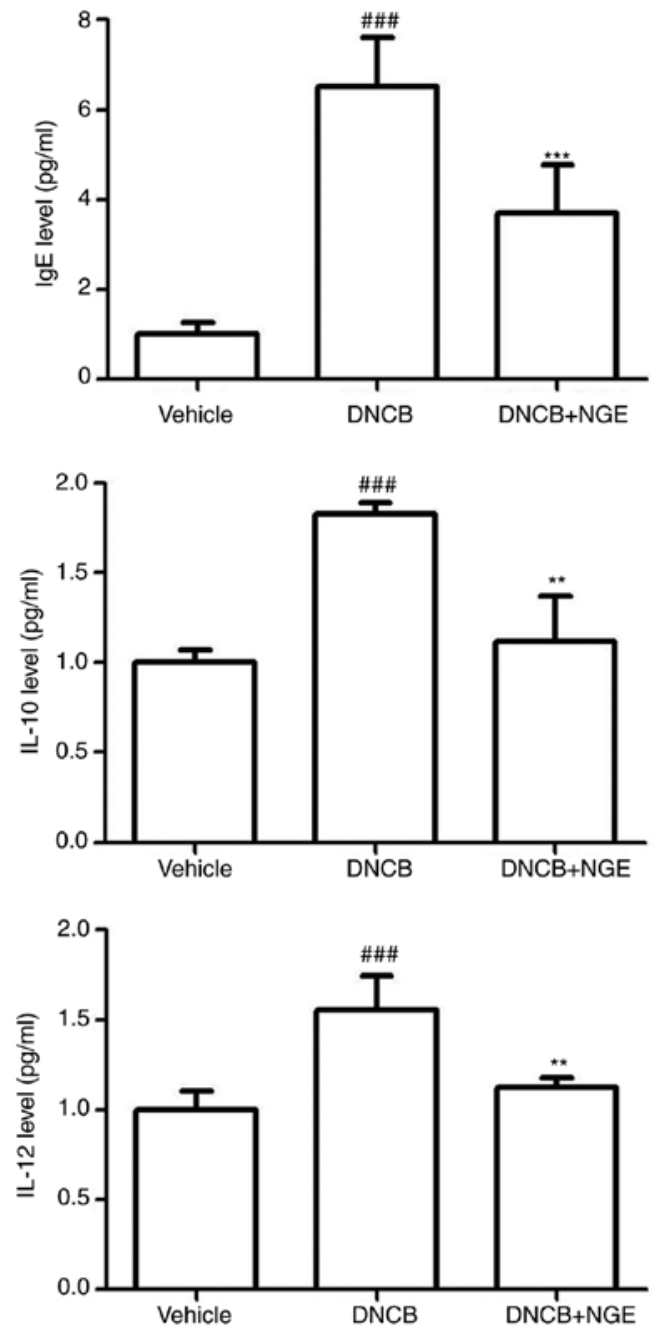

Figure 6. Effect of NGE on DNCB-induced plasma IgE and cytokine levels. Blood samples were collected, and the plasma was isolated. The plasma levels of IgE, IL-10, and IL-12 in the indicated groups were measured using an enzyme-linked immunosorbent assay. The data are presented as the mean \pm standard error of the mean. ${ }^{\# \#} \mathrm{P}<0.001$, compared with the vehicle group; ${ }^{* *} \mathrm{P}<0.01$ and ${ }^{* * * *} \mathrm{P}<0.001$, compared with the DNCB-stimulated group. NGE, nok-gol; DNCB, 2,4-dinitrochlorobenzene; IgE, immunoglobulin E; IL, interleukin.

at the site of ointment application. It has been reported that the long-term use of corticosteroids results in treatment resistance $(43,44)$. The currently used medications include antihistamines, steroids and immunosuppressants, however, these medications show various limitations in treatment efficacy (6). Therefore, the identification of novel compounds which effectively treat $\mathrm{AD}$ is urgently required.

With the aim of developing an appropriate treatment agent for AD using a natural substance, the present study performed an in vivo experiment using BALB/c mice to assess the anti-AD effect of NGE. The results showed that NGE suppressed DNCB-induced AD in the BALB/c mice. As a herbal medicine, NGE may not have substantial side effects when used to treat $\mathrm{AD}$.

In conclusion, the present study revealed for the first time, to the best of our knowledge, that NGE, which is derived from an anti-inflammatory traditional medicine, alleviates AD-like inflammatory symptoms in mice by suppressing the production 
of $\mathrm{CD} 4^{+} \mathrm{T}$ cells, mast cells, eosinophils and proinflammatory cytokines. These results suggest that NGE may be a useful drug for the treatment of $\mathrm{AD}$.

\section{Acknowledgements}

Not applicable.

\section{Funding}

This study was supported by grants from the Korean Medicine R\&D Project of the Ministry of Health and Welfare (grant nos. HI12C1889 and HI13C0530) and Nongshim Corporation (grant no. 20121086).

\section{Availability of data and materials}

All data and materials are described within the article. The corresponding author will provide data and materials upon request.

\section{Authors' contributions}

SHH, JMK, and S-GK conceived and designed the experiments; SHH, HIK, SJL and YSL performed the experiments; SHH and YCS analyzed the data; SHH and HSS contributed to the writing of the paper. All authors read and approved the final manuscript.

\section{Ethics approval and consent to participate}

All procedures performed on mice were approved by the Animal Care Center of Kyung Hee University [approval no. KHUASP (SE)-16-095]. All methods were performed in accordance with the relevant guidelines and regulations.

\section{Patient consent for publication}

Not applicable.

\section{Competing interests}

The authors declare that they have no competing interests.

\section{References}

1. Leung DY and Bieber T: Atopic dermatitis. Lancet 361: 151-160, 2003.

2. Spergel JM and Paller AS: Atopic dermatitis and the atopic march. J Allergy Clin Immunol 112: S118-S127, 2003.

3. Simon D, Braathen LR and Simon HU: Eosinophils and atopic dermatitis. Allergy 59: 561-570, 2004.

4. Rousset F, Robert J, Andary M, Bonnin JP, Souillet G, Chrétien I, Brière F, Pène $J$ and de Vries JE: Shifts in interleukin-4 and interferon-gamma production by $\mathrm{T}$ cells of patients with elevated serum IgE levels and the modulatory effects of these lymphokines on spontaneous IgE synthesis. J Allergy Clin Immunol 87: 58-69, 1991.

5. Bieber T: Atopic dermatitis. Ann Dermatol 22: 125-137, 2010.

6. Gleich GJ: Mechanisms of eosinophil-associated inflammation. J Allergy Clin Immunol 105: 651-663, 2000.

7. Holt PG, Macaubas C, Stumbles PA and Sly PD: The role of allergy in the development of asthma. Nature 402: B12-B17, 1999.

8. Leiferman KM: Eosinophils in atopic dermatitis. Allergy 9: 20-26, 1989.
9. Ogawa K, Hashida R, Miyagawa M, Kagaya S, Sugita Y, Matsumoto K, Katsunuma T, Akasawa A, Tsujimoto G and Saito H: Analysis of gene expression in peripheral blood eosinophils from patients with atopic dermatitis and in vitro cytokine-stimulated blood eosinophils. Clin Exp Immunol 131: 436-445, 2003.

10. Hanifin JM, Cooper KD, Ho VC, Kang S, Krafchik BR, Margolis DJ, Schachner LA, Sidbury R, Whitmore SE, Sieck CK, et al: Guidelines of care for atopic dermatitis, developed in accordance with the American Academy of Dermatology (AAD)/American Academy of Dermatology Association 'Administrative Regulations for Evidence-Based Clinical Practice Guidelines'. J Am Acad Dermatol 50: 391-404, 2004.

11. Novak N, Valenta R, Bohle B, Laffer S, Haberstok J, Kraft S and Bieber T: FcepsilonRI engagement of Langerhans cell-like dendritic cells and inflammatory dendritic epidermal cell-like dendritic cells induces chemotactic signals and different T-cell phenotypes in vitro. J Allergy Clin Immunol 113: 949-957, 2004.

12. Ong PY and Leung DY: Immune dysregulation in atopic dermatitis. Curr Allergy Asthma Rep 6: 384-389, 2006.

13. Homey B, Steinhoff M, Ruzicka T and Leung DY: Cytokines and chemokines orchestrate atopic skin inflammation. J Allergy Clin Immunol 118: 178-189, 2006.

14. Leung DY, Boguniewicz M, Howell MD, Nomura I and Hamid QA: New insights into atopic dermatitis. J Clin Invest 113: 651-657, 2004.

15. Dearman RJ, Basketter DA and Kimber I: Differential cytokine production following chronic exposure of mice to chemical respiratory and contact allergens. Immunology 86: 545-550, 1995.

16. Dearman RJ, Basketter DA and Kimber I: Characterization of chemical allergens as a function of divergent cytokine secretion profiles induced in mice. Toxicol Appl Pharmacol 138: 308-316, 1996.

17. Warbrick EV, Dearman RJ, Basketter DA and Kimber I: Analysis of interleukin 12 protein production and mRNA expression in mice exposed topically to chemical allergens. Toxicology 132: 57-66, 1999.

18. Choi HS, Kim SR, Hong SH, Ku JM, Kim MK, Seo HS, Cho SG, Shin S, Shin YC and Ko SG: Water extract of deer bones activates macrophages and alleviates neutropenia. Evid Based Complement Alternat Med 2013: 617302, 2013.

19. Du CN, Min AY, Kim HJ, Shin SK, Yu HN, Sohn EJ, Ahn CW, Jung SU, Park SH and Kim MR: Deer bone extract prevents against scopolamine-induced memory impairment in mice. J Med Food 18: 157-165, 2015.

20. Li YJ, Kim TH, Kwak HB, Lee ZH, Lee SY and Jhon GJ: Chloroform extract of deer antler inhibits osteoclast differentiation and bone resorption. J Ethnopharmacol 113: 191-198, 2007.

21. Kuo CY, Wang T, Dai TY, Wang CH, Chen KN, Chen YP and Chen MJ: Effect of the velvet antler of formosan sambar deer (Cervus unicolor swinhoei) on the prevention of an allergic airway response in mice. Evid Based Complement Alternat Med 2012: 481318, 2012.

22. Dai TY, Wang CH, Chen KN, Huang IN, Hong WS, Wang SY, Chen YP, Kuo CY and Chen MJ: The antiinfective effects of velvet antler of formosan sambar deer (Cervus unicolor swinhoei) on staphylococcus aureus-infected mice. Evid Based Complement Alternat Med 2011: 534069, 2011.

23. Hong SH, Ku JM, In Kim H, Ahn CW, Park SH, Seo HS, Shin YC and Ko SG: The immune-enhancing activity of Cervus nippon mantchuricus extract (NGE) in RAW264.7 macrophage cells and immunosuppressed mice. Food Res Int 99: 623-629, 2017.

24. Kang SK, Kim KS, Kim SI, Chung KH, Lee IS and Kim CH: Immunosuppressive activity of deer antler extracts of Cervus korean TEMMINCK var. mantchuricus Swinhoe, on type II collagen-induced arthritis. In Vitro Cell Dev Biol Anim 42: 100-107, 2006.

25. Kim KS, Choi YH, Kim KH, Lee YC, Kim CH, Moon SH, Kang SG and Park YG: Protective and anti-arthritic effects of deer antler aqua-acupuncture (DAA), inhibiting dihydroorotate dehydrogenase, on phosphate ions-mediated chondrocyte apoptosis and rat collagen-induced arthritis. Int Immunopharmacol 4: 963-973, 2004.

26. Lee H, Choi HS, Park Y, Ahn CW, Jung SU, Park SH and Suh HJ: Effects of deer bone extract on the expression of pro-inflammatory cytokine and cartilage-related genes in monosodium iodoacetate-induced osteoarthritic rats. Biosci Biotechnol Biochem 78: 1703-1709, 2014.

27. Galli SJ, Tsai M and Piliponsky AM: The development of allergic inflammation. Nature 454: 445-454, 2008. 
28. Ku JM, Hong SH, Kim HI, Seo HS, Shin YC and Ko SG: Effects of Angelicae dahuricae radix on 2,4-dinitrochlorobenzene-induced atopic dermatitis-like skin lesions in mice model. BMC Complement Altern Med 17: 98, 2017.

29. Liu FT, Goodarzi H and Chen HY: IgE, mast cells, and eosinophils in atopic dermatitis. Clin Rev Allergy Immunol 41: 298-310, 2011.

30. Lubach D, Bensmann A and Bornemann U: Steroid-induced dermal atrophy. Investigations on discontinuous application. Dermatologica 179: 67-72, 1989.

31. Reitamo S, Rissanen J, Remitz A, Granlund H, Erkko P, Elg P, Autio P and Lauerma AI: Tacrolimus ointment does not affect collagen synthesis: Results of a single-center randomized trial J Invest Dermatol 111: 396-398, 1998

32. Werfel T, Allam JP, Biedermann T, Eyerich K, Gilles S, Guttman-Yassky E, Hoetzenecker W, Knol E, Simon HU, Wollenberg A, et al: Cellular and molecular immunologic mechanisms in patients with atopic dermatitis. J Allergy Clin Immunol 138: 336-349, 2016.

33. Kawakami T, Ando T, Kimura M, Wilson BS and Kawakami Y: Mast cells in atopic dermatitis. Curr Opin Immunol 21: 666-678, 2009.

34. Metz M, Grimbaldeston MA, Nakae S, Piliponsky AM, Tsai M and Galli SJ: Mast cells in the promotion and limitation of chronic inflammation. Immunol Rev 217: 304-328, 2007.

35. Theoharides TC, Kempuraj D, Tagen M, Conti $\mathrm{P}$ and Kalogeromitros D: Differential release of mast cell mediators and the pathogenesis of inflammation. Immunol Rev 217: 65-78, 2007.
36. Kalesnikoff $\mathbf{J}$ and Galli SJ: New developments in mast cell biology. Nat Immunol 9: 1215-1223, 2008.

37. Miller MD, Hata S, De Waal Malefyt R and Krangel MS: A novel polypeptide secreted by activated human T lymphocytes. J Immunol 143: 2907-2916, 1989.

38. Zipfel PF, Balke J, Irving SG, Kelly K and Siebenlist U: Mitogenic activation of human $\mathrm{T}$ cells induces two closely related genes which share structural similarities with a new family of secreted factors. J Immunol 142: 1582-1590, 1989.

39. Hamid Q, Boguniewicz M and Leung DY: Differential in situ cytokine gene expression in acute versus chronic atopic dermatitis. J Clin Invest 94: 870-876, 1994.

40. Ahmadzadeh M, Hussain SF and Farber DL: Heterogeneity of the memory CD4 T cell response: Persisting effectors and resting memory T cells. J Immunol 166: 926-935, 2001.

41. Hershey GK, Friedrich MF, Esswein LA, Thomas ML and Chatila TA: The association of atopy with a gain-of-function mutation in the alpha subunit of the interleukin-4 receptor. $\mathrm{N}$ Engl J Med 337: 1720-1725, 1997.

42. Matsumoto $\mathrm{K}$ and Saito $\mathrm{H}$ : The role of eosinophils in asthma: Sarastro or the Queen of the Night? Int Arch Allergy Immunol 125: 290-296, 2001.

43. Gottlieb AB: Therapeutic options in the treatment of psoriasis and atopic dermatitis. J Am Acad Dermatol 53: S3-S16, 2005.

44. Del Rosso J and Friedlander SF: Corticosteroids: Options in the era of steroid-sparing therapy. J Am Acad Dermatol 53: S50-S58, 2005 . 